\title{
Analyzing Foreign Investors Behavior in the Emerging Stock Market: Evidence from Qatar Stock Market
}

\author{
Elsayed Elsiefy ${ }^{1} \&$ Moustafa Ahmed AbdElaal ${ }^{2}$ \\ ${ }^{1}$ Professor of Finance, Faculty of Islamic Studies, Hamad Bin Khalifa University -Qatar Foundation, Faculty of \\ Commerce- Alexandria University, Egypt \\ ${ }^{2}$ Department of business administration, Faculty of Commerce- Alexandria University - Egypt \\ Correspondence: Prof. Dr. Elsayed Elsiefy, Professor of Finance, Faculty of Commerce- Alexandria University, \\ Egypt
}

Received: August 28, 2017

Accepted: September 27, 2017

Online Published: September 30, 2017

doi:10.5430/afr.v6n4p197

URL: https://doi.org/10.5430/afr.v6n4p197

\begin{abstract}
This paper examines the effect of the foreign investors fund flow into the domestic stock market. We investigated whether foreign investors are only herders or if they have also the ability to push the market up and down. To answer this question, we include investors' types as an independent factor in Markov-Switching Model used by Hamilton (1989) to examine the asymmetric effect of the foreign investors during the bull and bear states. Empirical results from Qatar Stock Market suggested that foreign institutional traders are only herding in the market and they cannot play the role of the market maker. We have also found that neither foreign investors nor domestic investors have the ability to switch the regime of the market. The time-varying relationship between the various investors' types has been investigated. We reported that, although the correlation matrixes of the investors' categories with the market are time-varying, the foreign institutional trader is still the leader of the market during the bull (bear) states of the market. Finally, we proposed some procedures to minimize the harmful of the foreign investors bad trading.
\end{abstract}

Keywords: Foreign Investors Behavior, Stock Market, Bull Market, Bear Market. Qatar Stock Market, Herd behavior, Time-varying correlation matrixes, Switching in Regime

\section{Introduction}

Foreign investing is especially worrisome because of its bad behavioral reputation, especially after the Asian financial crisis of 1997 crisis. Many studies, such as Brennan and Cao (1997) and Froot et al. (2001) have investigated the behaviors of foreign traders in domestic markets to determine their effect on stock market efficiency. There is no doubt that the 1997 financial crisis made researchers more interested in observing international funds movements. It is thought that foreign investors cause herding behaviors due to the effect of past returns in purchasing and selling their stocks, which is known as positive and negative feedback trade. So investors buy when the market bull up and sell when the market bear down. Choe et al. (1999) examine the feedback trading effect from foreign investors before and during Korea's economic crisis; they found that foreign traders had a positive effect before Korea's economic crisis but not during Korea's economic crisis. The study of Karolyi (2002) supports the results of the Choe study, Karolvi found that foreign investors have positive feedback trading before the crisis in Japan in 1997 and this effect disappeared during the crisis. Also, many studies, such as Brennan and Cao (1997) and Froot et al. (2001), have found evidence of positive feedback trading in international flows.

Kamesaka et al.(2003) analyzed Japans' stock market using weekly data to study the pattern of foreign investors, individual investors, and five types of institutional investors. They found that both foreign and individual investors have positive feedback behaviors.

Many authors concluded that foreign investors have a significant role in moving the stock market up and down by herding on the same trends of market and act as free riders. Some previous studies, such Kamesaka et al.(2003), measured herding using Pearson correlation coefficients between the investor group and between each investor category and the market return. Choe et al. (1999) used different measures to extract the herding behaviors in the Korean market. They assumed that foreign investors lead market trends by momentum investing. In our study we will examine whether foreign investors lead the market by using a nonlinear Markov-Switching Model. Many studies investigate the relationship between economic factors and stock market returns using linear models, such as the OLS 
regression. Unfortunately, the explanatory power of this model may be weak as a result of the dynamic nature of the stock markets and the changing trends of it, especially when the factors, which affect market returns, have asymmetric effects according to the business cycle. In this study, we consider the business-cycle factor by using the Markov-Switching Model, which has the ability to extract the relationship between several factors considering two states. Interestingly, incorporating regime switching in the process of measuring the relation between the various investors categories and the stock market return enables us to obtain more accurate evidence about the behaviors of the different categories of investors in both bear and bull markets, which is useful to policy makers in processing economic policies.

To infer whether foreign investors lead the market only during the market state or if they could also transfer the market from one state to other, for instance from bull state to bear state, we use a time-varying transition probability matrix. The previous time-varying matrix enables us to determine the ability of foreign investors to affect the dynamics of switching in regime of stock market return. The significant parameters of both the Markov Model and time-varying transition probability matrix mean that foreign investors do not have a feedback trading behavior and that they have full control on market movement. On the other hand, significant parameters of the Markov Model and non-significant parameters of the time-varying transition probability matrix at the same time means that foreign investors do not have full control on the market and they only have positive feedback trading behavior which destabilizes the stock market. Moreover, we will investigate the time varying relation between the various investors' categories and the stock market return. In other words, if some investors really lead the market, is this leadership position stable over the time or the leaderships' positions change over the time. To examine this issue, we investigate the time varying correlations' coefficient matrixes between the various investors' types and the stock market return.

The structure of this article is as follows. Section 1 displays literature about foreign investors' feedback trading behaviors all over the world markets. Section two and three consider our study's data and examine the stationary results. Section four and five investigate the characteristics of the bull and bear market states in the Qatari Market and determine whether foreign investors could lead the market during the bull and bear states. Section six considered the effects of foreign investor's trade on the dynamics of switching in regime. Section seven discusses in more details the herding behavior of foreign investors. Section 8 analyzes correlation matrixes of the time-varying correlation of the four investors' types with the stock market return. In section 9, we display the importance of study and recommendations, while section 10 shows the future research. Finally, Section 11 presents the summary.

\subsection{Foreign Investor's Transactions and Herding Behavior}

Many studies investigated the feedback trading behavior or herding. For example, Chang, C et al. (2010) examined the co-movement between investors in the Taiwan stock market and concluded that when the qualified foreign institutional investors (QFIIs) in an emerging equity market increase (decrease) their weightings in particular sectors, this drive the dealers', margin traders', and mutual funds' holdings similar increase (decrease) during the same period instead of using return-risk analysis. Shyu, J et al. (2010) investigates the herding behavior of both individual and institutional investors in the Taiwan's stock market from January 1999 to December 2004. They divided the institutional investors into foreign and domestic traders. They found that the foreign institutional investors have a tendency to herd. However, they found also that the domestic mutual-funds investors have the strongest tendency to herd. Wu, W et al. (2011) analyzed the role of QFIIs in the China's share market; are they long-run investors or they are only speculators? The empirical results of the study showed that QFIIs are actual long-run investors and their ownership could improve the development of the country. Patnaik, I et al. (2013) investigates the effects of foreign investors' inflows and outflows on the local market in India during the good and bad days. They found that only in the good days, foreign transactions lead local investors to buy, which causes positive feedback effect; however, in the bad days there is no evidence support the existence of the previous effect. Choi et al. (2014) examined herding behavior of institutional investors in 41 countries and found significant herding behavior all over these 41 markets. They also found that the main reasons for this behavior are from fundamental information. Jirasakuldech et al. (2015) investigated the foreign and domestic behavior during the 3 crises in the Thailand stock market and showed that foreign investors have followed positive feedback investment trading strategy during the entire sample period of the study.

\section{Data}

In this study we used monthly data of DSM20 Index, which reflects a capitalization-weighted index of the 20 highest capitalized and liquid companies traded in the Qatar Exchange. DSM20 was used as a proxy for stock market return. We used the data from January 2008 to October 2012. 
Figure (A) the monthly data of DSM20 Index of the Qatari stock market during the period from 2008 until 2012.

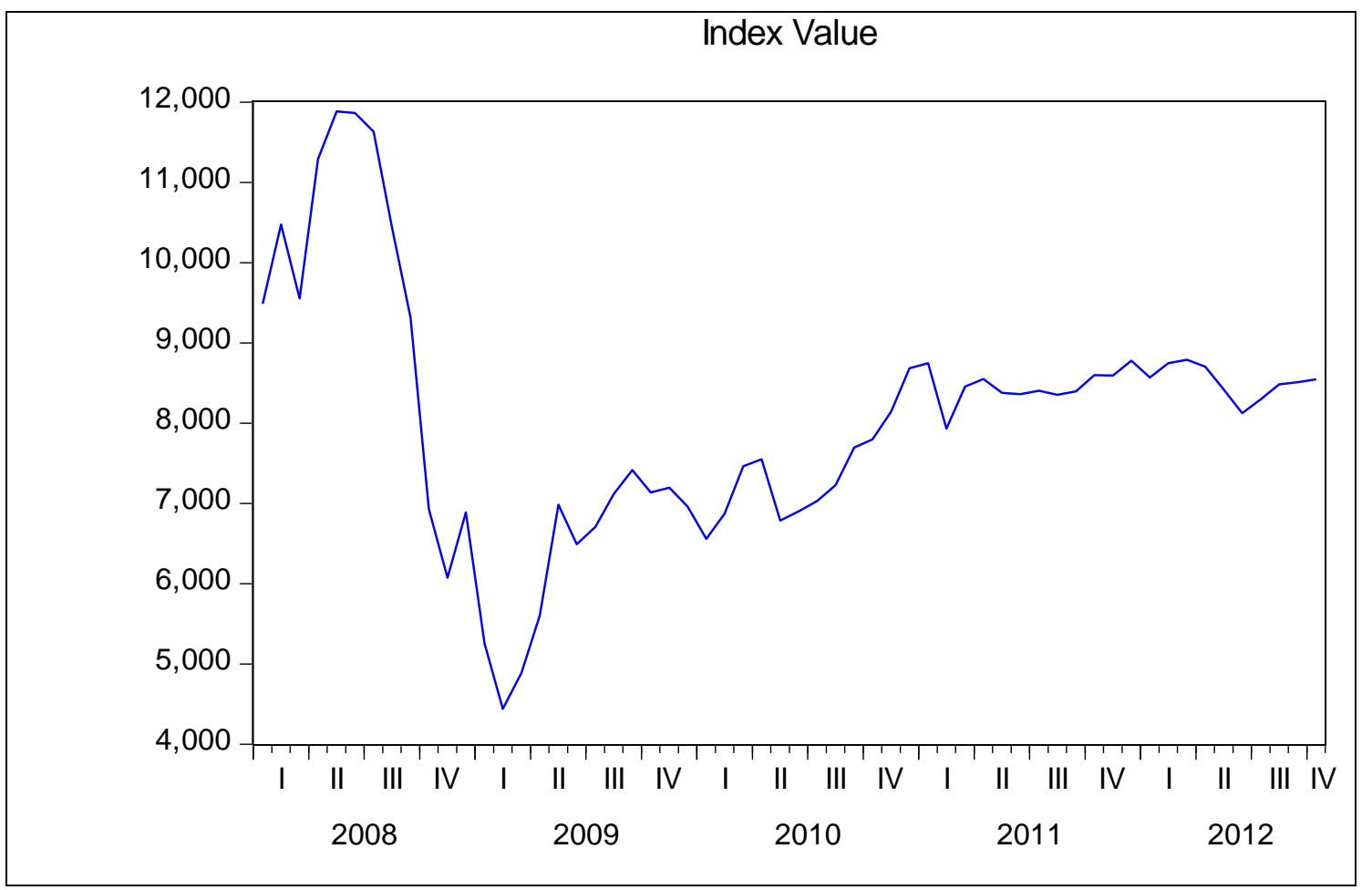

The graph shows monthly data of DSM20 Index of the Qatari stock market during the period from 2008 until 2012. As it is obvious from the chart, DSM20 Index bears dramatically during the second part in 2008 while the world's financial crisis has reached the peak. The 2008 crash was followed by rises during the period from 2009 until 2012. The high volatility and trends changing of the Qatari stock market illustrate the importance of studying this issue and know who the leaders of the market are during this period.

Regarding the investors' flows, the buying and selling streams were sorted into four types: Foreign Individuals, Foreign Institutions, Qatari Institutions, and Qatari Individuals. To calculate the Net Investment Flow for each group, the following equation has been used:

\section{NetTradingFlows $=$ PurchasingValue - SellingValue}

The second important step is to calculate the change in every investor type trading, which is computed using following formula:

(NetTradingFlows $_{t}$-NetTradingFlows N-1 $_{t}$ )/NetTradingFlows t $_{t-1}$.

Therefore, the change in the trading of our four investors categories will be measured using the following variables: Fins D $_{\mathrm{t}}$, FindD $\mathrm{t}$, QindD $\mathrm{t}$, and QinsD $_{\mathrm{t}}$.

Fins $\mathrm{D}_{t}$ reflects the change in the monthly Foreign Institutions Net Trading value. Find $\mathrm{D}_{t}$ reflects the change in the monthly Foreign Individuals Net Trading value. Qins $\mathrm{D}_{\mathrm{t}}$ reflects the change in the monthly Qatari Institutions Net Trading value. QindD ${ }_{t}$ reflects the change in the monthly Qatari Individuals Net Trading value.

\section{Examining Time Series Stationarity and Serial Correlation}

To examine our data validity, two tests were used. First, the Augmented-Dicky-Fuller (ADF) test, which tests the existence of the unit root in the time series, has been used. The second test was the Durbin Watson (DW) test, which was used to examine the presence of serial correlation in the indices time series. Table (1) summarizes the results of the previous two tests of ADF, and DW for DSM20 Index and the Net Investment Flows time series of the four investors group of the study. Table (1) shows that all the data series used in the study do not have unit root or serial correlation except Qins $_{t}$, which is only stationary on the 2th difference rank, so we considered the second difference of Qins $_{t}$ in our models. 


\begin{tabular}{|c|c|c|c|c|c|c|c|}
\hline \multicolumn{8}{|l|}{ Table (1) } \\
\hline & \multicolumn{7}{|c|}{ ADI Unit Root Test and DW Stationary Tests results } \\
\hline & \multicolumn{6}{|c|}{ ADI Unit Root Test } & \multirow{3}{*}{ DW } \\
\hline \multirow{2}{*}{ Index } & \multirow[t]{2}{*}{ t-Statistic } & \multirow[t]{2}{*}{ P Value } & \multirow[t]{2}{*}{ Lags } & \multicolumn{3}{|c|}{ Test critical values } & \\
\hline & & & & $1 \%$ level & $5 \%$ level & $10 \%$ level & \\
\hline Find $D_{t}$ & -7.952395 & 0.0000 & 0 & -3.550396 & -2.913549 & -2.594521 & 2.017354 \\
\hline Fins $D_{t}$ & -7.555568 & 0.0000 & 0 & -3.550396 & -2.913549 & -2.594521 & 2.000437 \\
\hline Qind $_{t}$ & -7.301613 & 0.0000 & 0 & -3.550396 & -2.913549 & -2.594521 & 1.952318 \\
\hline Qins $_{t}$ & -1.316435 & 0.6161 & 0 & -3.550396 & -2.913549 & -2.594521 & 1.043239 \\
\hline $\operatorname{Qins}_{t}(1)$ & -2.349782 & 0.1605 & 1 & -3.552666 & -2.914517 & -2.595033 & 1.069281 \\
\hline $\operatorname{Qins}_{t}(2)$ & -4.372005 & 0.0009 & 2 & -3.555023 & -2.915522 & -2.595565 & 1.151271 \\
\hline
\end{tabular}

\section{Characterizing the Qatari Market}

In this section, we examine the characteristics of the bull and bear market states in the Qatari Market. Many studies have concluded that bull markets have a long positive duration and low variance. The previous researches have also found that bear market have a short duration and high variance. To examine the properties of the Qatari Market, the Hamilton (1989) model will be used.

$$
R_{M t}=\mu_{S t}+\varepsilon_{t}, \quad \quad N\left(0, \sigma_{S t}^{2}\right) .
$$

$R_{M t}$ is the Market Index return in time t. Terms $\mu_{S t}, \sigma_{S t}^{2}$ are respectively the state-dependents mean and variance of $R_{M t}$. $S_{t}$ is an state variable which equal 0 or 1 according to market state, so $S_{t} \in\{0,1\}$. This model also has normally distributed error.

Table (2) part (1) shows that the standard error of the bear market is higher in the bull market, which are 0.0327 and 0.0097 respectively.

Table (2) part (1) also illustrates the differences in the return of the Qatari Market's states. The return values of the bull and bear states displayed in the table were 0.019817 , and -0.16539 respectively. This corresponds with the previous studies.

Figure (1) supports the opinion that the bull market has a long duration while the bear Market has a short duration. The first part in Figure (1) shows the probability of continuation in bull state while the second part shows the probability of continuation in bear state. So the probability of being in the bull market is more than the probability of being in bear Market.

To illustrate the previous argument numerically, the following Constant Markov transition probabilities matrix should be found:

$$
P_{(t)}=\left[\begin{array}{cc}
p^{00} & 1-p^{11} \\
1-p^{00} & p^{11}
\end{array}\right] \quad \ldots .
$$

Where, $p_{t}^{i j}=P\left(S_{t}=j \mid S_{t-1}=i\right)$,

Interestingly, the transition probabilities matrix, which were used by Hamilton (1989) include functions containing the binary dependent variable and the probability variable, so the following logistic function will be used:

$$
\begin{aligned}
\mathrm{p}^{00} & =\frac{\exp \left(\theta_{0}\right)}{1+\exp \left(\theta_{0}\right)} \ldots \ldots \ldots \\
\mathrm{p}^{11} & =\frac{\exp \left(\gamma_{1}\right)}{1+\exp \left(\gamma_{1}\right)} \ldots \ldots \ldots
\end{aligned}
$$

Where $\theta_{0}$, and $\gamma_{1}$ show the functions of the mean return $\left(\mu_{0 t}+\varepsilon_{t}\right)$, and $\left(\mu_{1 t}+\varepsilon_{t}\right)$. The results in table (2) show the outputs of running equations (3) and (4). The table shows that there is considerable state dependence in the transition probabilities. The probability of remaining in the bull regime $\left(p^{00}\right)$ is higher than the probability of persist in the bear state $\left(\mathrm{p}^{11}\right)$ (0.9589for the bull state, 0.5982 for the bear state). So it is expected that the duration in the bull regime is higher that the one in the bear state. Figure (1) in the appendix displays the filtered regime probability of 
being in the bull state when $\mathrm{P}(\mathrm{S}(\mathrm{t})=0)$, while Figure (2) displays the filtered regime probability of being in the bear state when $\mathrm{P}(\mathrm{S}(\mathrm{t})=1)$.

\section{Table(2)}

Part (1) shows the characteristics of the bull and bear market states in the Qatari Market.

Part (2) gives a breakdown of the different investors' types in the Qatari stock market and their effect on the stock market return considering the two market regimes, bull and bear states.

\begin{tabular}{cllll}
\hline & part (1) & & part (2) & \\
\hline Parameter & MS & p-value & A-MS & -value \\
\hline$\mu_{0}$ & 0.019817 & 0.0417 & 0.01337 & 0.2049 \\
& $(0.0097)$ & & $(0.010548)$ & \\
\hline$\mu_{1}$ & -0.16539 & 0.0000 & -0.0737 & 0.0277 \\
& $(0.0327)$ & & $(0.033507)$ & \\
\hline$\beta_{10^{-}}$FindD & & & -0.00158 & 0.4833 \\
& & & $(0.002259)$ & \\
\hline$\beta_{20^{-}}$FinsD $_{\mathrm{t}}$ & & 0.005400 & 0.0483 \\
& & & $(0.002735)$ & \\
\hline$\beta_{30^{-}}$ & & -0.000248 & 0.7909 \\
$\mathrm{QindD}_{\mathrm{t}}$ & & $(0.000936)$ & \\
\hline$\beta_{40^{-}}$ & & -0.000210 & 0.5688 \\
$\mathrm{Qins}_{\mathrm{t}}(2)$ & & $(0.000369)$ & \\
\hline
\end{tabular}

\begin{tabular}{llll}
\hline$\beta_{11}-$ FindD $_{\mathrm{t}}$ & & 0.0636 & 0.0000 \\
& & $(0.014643)$ & \\
\hline$\beta_{21^{-}}$FinsD $_{\mathrm{t}}$ & & 0.00028 & 0.0384 \\
& & $(0.000137)$ & \\
\hline$\beta_{31^{-}}$ & & -0.00295 & 0.2833 \\
$\mathrm{QindD}_{\mathrm{t}}$ & & $(0.002759)$ & \\
\hline$\beta_{41^{-}}$ & & 0.00609 & 0.0737 \\
$\mathrm{Qins}_{\mathrm{t}}(2)$ & & $(0.003405)$ & \\
\hline $\mathrm{p}_{\mathrm{t}}^{00}$ & 0.9589 & 0.8596 & \\
\hline \multicolumn{1}{c}{$\mathrm{p}_{\mathrm{t}}^{11}$} & 0.5982 & 0.3029 & \\
\hline LogLik & 66.165 & 68.43 & \\
\hline$A I C$ & -2.109167 & -1.979710 & \\
\hline$S C$ & -1.931542 & -1.509539 & \\
\hline$H Q C$ & -2.039978 & -1.797426 & \\
\hline$D W$ & 1.968292 & 1.829418 & \\
\hline
\end{tabular}

\section{Do Foreign Investors Lead the Market during Bull (Bear) State?}

As previously displayed, foreign investors are always blamed for raising the market volatility. The government should balance between the importance of foreign direct investments (FDI) and the risk of foreign funds movements in the domestic stock market. 
This section will examine the effect of foreign fund streams over domestic Qatari stock market return. We will model this relationship via two regimes, bull and bear states. There is no doubt that many studies were concerned with the factors, such as interest rates and economic indicators, which affect stock market performance. A great number of these studies used the linear forms to model these relationships. Unfortunately, the explanatory power of these models is weak in the case of unstable market, so non-linear models may be more accurate than the linear models in these cases.

One of the advantages of a non-linear model is that it enables us to include business cycles in the description of stock market performance. Hamilton (1989) used the Markov-Switching Model to explain business cycles and transition probability related to the expansion and recession phases. Durland and McCurdy (1994) adjusted this model and allowed duration to affect transition-probabilities. Chen.(2005) used a modified version of Hamilton (1989) to find the effect of monetary policy on stock returns. He found that monetary policy has a much larger effect during bear-market periods than during bull-market periods.

In this paper we will adjust the model suggested in Hamilton (1989) study to find the effects of foreign funds streams on the domestic market. Investors will be categorized into 4 groups: Foreign Institutions, Foreign Individuals, Qatari Institutions, and Qatari Individuals. We have adapted Hamiltons' (1989) algorithm to include investor's categories variables. Using the Markov-Switching Model, we considered the markets' two states to extract more accurate results. We have tried to answer the following question: Do foreign investors lead the Qatari market during bull (bear) state? The following formula will be used:

$$
R_{M t}=\mu_{S t}+\beta_{1 S, t} \text { Find }_{t}+\beta_{2 S, t} \text { Fins }_{t}+\beta_{3 S, t} \text { Qind }_{t}+\beta_{4 S, t} \text { Qins }_{t}+\varepsilon_{t}, . .
$$

The second part in Table (2) gives a breakdown of the different investors' types in the Qatari stock market and their effect on the stock market return considering the two market regimes, bull and bear states.

According to the table, there is an obvious significant effect of foreign institutional investors trades over the Qatari stock market return during bull and bear states whose coefficient are 0.0054 and 0.00028 respectively, while foreign individual investors have only significant effect during bear state at coefficient 0.0636 .

On the other hand, the results show that Qatari Individuals do not have significant effects during the bull or the bear state; while Qatari institutions have a significant effect only in the bear state. So we can conclude that foreign institutional traders are the smart investors in the Qatari stock market.

\section{The Effect of Foreign Investors Trade on the Dynamics of Switching in Regime}

Hamilton (1989) is criticized for assuming fixed transitional probabilities. Henceforth, the probability of transition from one market state to another is fixed and could not be changed. In the real world, these probabilities are not constant and there are factors that affect these parameters causing bull and bear phases, as well as expansion and contraction phases. Hamilton (1989) depended mainly on a fixed-transition-probability (FTP) Markov-switching model to predicting market states. So he has allowed for economic variables to be used in predicting economic growth. In our study we have allowed for the investors categories to affect the stock market return; unfortunately, the FTP model does not consider the change in transitional probabilities for Switching in Regime. The explanatory of FTP may consequently be weak.

Filardo (1999) has solved the previous problem by using a time-varying-transition-probability (TVTP) Markov-switching model and allow the probability of switching between bull markets vs. bear markets to depend on independent variables. In this section we have modified Filardo (1999) model to include investor's types as an independent variable in the algorithm of predicting the Switching in Regime. FTP was replaced with Time-Varying Transition Probability Matrix (TVTP). The following time - varying transition probability matrix should be found:

$$
\mathrm{P}_{(\mathrm{t})}=\left[\begin{array}{cc}
\mathrm{p}_{\mathrm{t}}^{00}\left(\mathrm{Z}_{\mathrm{t}-1}\right) & 1-\mathrm{p}_{\mathrm{t}}^{11}\left(\mathrm{Z}_{\mathrm{t}-1}\right) \\
1-\mathrm{p}_{\mathrm{t}}^{00}\left(\mathrm{Z}_{\mathrm{t}-1}\right) & \mathrm{p}_{\mathrm{t}}^{11}\left(\mathrm{Z}_{\mathrm{t}-1}\right)
\end{array}\right]
$$

Where, $p_{t}^{i j}\left(Z_{t-1}\right)=P\left(S_{t}=j \mid S_{t-1}=i, Z_{t-1, v}\right)$, and $Z_{t-1, v}$ reflect the trader categories. We have constructed the TVTP to predict the Switching in Regime in the stock market business cycle. We have used the investors' categories as an independent variables affecting turning point. So, the probability of switching from one regime to other $\left(p_{t}^{i j}\right)$ will be the dependent factor. The functions of the transition probabilities are then specified as follows:

$$
p_{t}^{00}\left(Z_{t-1}\right)=\frac{\exp \left(\theta_{0}+\theta_{1} Z_{t-1,1}+\cdots+\theta_{v} Z_{t-1, v}\right)}{1+\exp \left(\theta_{0}+\theta_{1} Z_{t-1,1}+\cdots+\theta_{1 v} Z_{t-v}\right)} \ldots \cdots \cdots \cdots \cdots
$$




$$
p_{t}^{11}\left(Z_{t-1}\right)=\frac{\exp \left(\gamma_{0}+\gamma_{1} Z_{t-1,1}+\cdots+\gamma_{v} Z_{t-1, v}\right)}{1+\exp \left(\gamma_{0}+\gamma_{1} Z_{t-1}+\cdots+\gamma_{v} Z_{t-1, v}\right)} \ldots \ldots \ldots \ldots \ldots
$$

$v$ represents the investors groups. Table (3) summarizes the results of the logistic functions (6) and (7). The question is whether the investor types' predictors significantly influence the probability of a phase shift in stock market return.

Columns (1) and (2) illustrate the results of regressing both of Find $\mathrm{D}_{\mathrm{t}-1}$ and Fins $_{\mathrm{t}-1}$ against the probability of shifting regime of the Qatari Stock Market. The results show that both FindD $\mathrm{D}_{\mathrm{t}-1}$ and Fins $_{\mathrm{t}-1}$ have no significant effect on the switching regime of the Qatari stock market. We have selected the lags of both FindD $\mathrm{t}_{t}$ and Fins $\mathrm{D}_{t}$ in this regression model after considering the suggestions by both Akaike's Information Criterion (AIC) and Schwarz's Criterion (SC). In addition, Columns (3)and (4) display the coefficients of the relationships between the two Qatari investor's categories $\left(\mathrm{QindD}_{\mathrm{t}-1}\right.$ andQins $\mathrm{D}_{\mathrm{t}-1}(2)$ and the probabilities of the regime shifting in the Qatari stock market. The orders of lags in this model have been also selected according to AIC and SC criteria. The coefficients show that only Qatari individual traders have a strong effect on the switching regime during the bull state with coefficient -0.284315 , which means that there is a negative relationship between the Qatari individual flows and the probability of persistence in the bull regime $\left(\mathrm{p}^{00}\right)$. This result argues for the failure of Qatari individuals in predicting and timing the market Turning points. On the other hand, Qatari institutional traders do not have significant effects neither on the bull regime nor on the bear regime.

Regarding the graphs in the appendix, Figure (3) displays the Time-Varying Transition Probabilities after including foreign individuals and foreign institutions factors in the TVTM when $\operatorname{Pr}(\mathrm{S}(\mathrm{t})=0 \mid \mathrm{S}(\mathrm{t}-1)=0)$. Figure (4) displays the Time-Varying Transition Probabilities after including foreign individuals and foreign institutions factors in the TVTM when $\operatorname{Pr}(S(t)=1 \mid S(t-1)=1)$. Figure (5) shows the Time-Varying Transition Probabilities after including Qatari individuals and Qatari institutions factors in the TVTM when $\operatorname{Pr}(\mathrm{S}(\mathrm{t})=0 \mid \mathrm{S}(\mathrm{t}-1)=0)$. Finally, Figure (6) provides the Time-Varying Transition Probabilities after including Qatari individuals and Qatari institutions factors in the TVTM when $\operatorname{Pr}(\mathrm{S}(\mathrm{t})=1 \mid \mathrm{S}(\mathrm{t}-1)=1)$.

\section{Foreign Investors' Herding}

The previous analysis considered the effects of foreign investors' funds flows in the domestic stock market. Our paper investigated this issue via two discussions. First, we examined whether foreign investors traders lead the market during the bull (bear) state. Second, we investigated the effects of foreign transactions on switching regime of the stock market cycle. It was found that foreign institutions can only lead the market during bull (bear), while they do not affect shifting probabilities of the market. Foreign individuals, on the other hand, can lead the market only during the bear state, while Qatari individual investors do not have any effect on the bull state or on the bear state. It could be inferred that foreign institutions only herd on the information that others do not have, which could be called "speculation", according to Kyle (1985) and Froot et al. (1992). Since all foreign investors' types could not affect switching regimes in the Qatari market, they do not have the ability to control the prices of the stocks, which means that we could not call them "market makers", according to Kyle (1985) and Froot et al. (1992) definition of market maker. Finally, it could be concluded that foreign investors have short horizons; they only herd the market for speculating purposes. In other words, we found that foreign investor's trading is associated with positive feedback, which destabilizes stock markets. 
Table (3) The Effect of Foreign Investors Trade on the Dynamics of Switching in Regime. The table summarizes the results of the logistic functions (6) and (7).

\begin{tabular}{|c|c|c|c|c|}
\hline & \multicolumn{2}{|c|}{ Find $D_{t-1}-F i n s D_{t-1}$} & \multicolumn{2}{|c|}{$\operatorname{Qind}_{t-1}-Q i n s D_{t-1}(2)$} \\
\hline & (1) & (2) & (3) & (4) \\
\hline Parameter & & p-value & & p-value \\
\hline$\mu_{00}$ & $\begin{array}{l}0.021474 \\
(0.010307)\end{array}$ & 0.0372 & $\begin{array}{l}0.003179 \\
(0.021219)\end{array}$ & 0.8809 \\
\hline$\mu_{11}$ & $\begin{array}{l}-0.158267 \\
(0.033242)\end{array}$ & 0.0000 & $\begin{array}{l}-0.000286 \\
(0.005637)\end{array}$ & 0.9596 \\
\hline$\theta_{0}$ & 3.137434 & 0.0013 & 15.899537 & 0.0000 \\
\hline$\theta_{1}$ & $\begin{array}{l}0.052005 \\
(0.182907)\end{array}$ & 0.7762 & $\begin{array}{l}-0.284315 \\
(0.010966)\end{array}$ & 0.0000 \\
\hline$\theta_{2}$ & $\begin{array}{l}0.005201 \\
(0.038784)\end{array}$ & 0.8933 & $\begin{array}{l}-1.560343 \\
(1.215952)\end{array}$ & 0.1994 \\
\hline$\gamma_{0}$ & -1.988346 & 0.2513 & -33.93583 & 0.8664 \\
\hline$\gamma_{1}$ & $\begin{array}{l}0.884977 \\
(1.455816)\end{array}$ & 0.5433 & $\begin{array}{l}-1.100964 \\
(7.152504)\end{array}$ & 0.8777 \\
\hline$\gamma_{2}$ & $\begin{array}{l}-8.548368 \\
(8.546798)\end{array}$ & 0.3172 & $\begin{array}{l}1.111627 \\
(7.479833)\end{array}$ & 0.8819 \\
\hline LogLik & 66.57021 & & 81.15454 & \\
\hline$D W$ & 2.068878 & & 1.538663 & \\
\hline$A I C$ & -1.985180 & & -2.453605 & \\
\hline$S C$ & -1.665456 & & -2.098356 & \\
\hline$H Q C$ & -1.860641 & & -2.315228 & \\
\hline
\end{tabular}

\section{Analyzing Correlation Matrixes}

It is known that in portfolio management, investigating correlation matrices is very important. The low correlation values between stocks are associated with low portfolio risk. On the other hand, it is very important to evaluate the relationships between investors in financial markets. In this section, we will try to achieve more understanding of the relations between the different investors' categories and stock market movements. As we have previously showed, foreign institutional investors lead the Qatari market during the bull and bear market, while foreign individual investors and Qatari institutions have a significant effect only in the bear state. Qatari individual investors have no effect on the market trends. We will try to investigate the correlation matrices to find what is known as "time varying correlation matrices", which measures the relation between the four different investors' categories' trades and the stock market trends. As it is known, the traditional correlation assumes that correlation (repetition correlation correlation) is constant over time. However, in the real world, many studies reported that correlation coefficients in the various stock markets are varying and are not constant. For example, Solnik (1995), Tse (2000), Engle and Sheppard (2001) tested the constant-correlation hypothesis in the international stock markets. In other words, they examined the correlation structure of the international stock markets. The results show that the correlations across the world stock market returns are time-varying and rejected the hypothesis of the constant-correlation. Solnik (1995) also found that markets could be more highly correlated in periods of high volatility. The studies of Solnik (2001), and Ang and Chen (2002) support the previous results that the correlation matrixes varies according to the markets' states.

In this paper, we do not investigate the correlation structure of stocks' returns; however, we will analyze the correlation matrices of the trading behavior of the different investors' categories in the Qatari market during the period from January 2008 to October 2012. We will try to answer the following questions: is the correlation between the different investors' categories and the stock index stable over the time, or it is volatile? What do the results mean? 


\subsection{Estimating Time Varying Correlation Matrices}

It is known that the first step in calculating the time varying correlation is determining the rolling window, which has the number $N$ of observations during the study period. The time varying correlation could be estimated with the following rolling model:

$$
\hat{\rho}_{i M, t}=\frac{\sum_{S=t-N}^{t-1}\left(c_{i, t}-\bar{c}_{i}\right)\left(c_{M, t}-\bar{c}_{M}\right)}{\sqrt{\sum_{S=t-N}^{t-1}\left(c_{i, S}-\bar{c}_{i}\right)^{2}\left(c_{M, S}-\bar{c}_{M}\right)^{2}}} \cdots
$$

Where $t=N+1, \ldots, T$. $c_{i, t}$ is the change of the trading value of the investor's category $i$ in the time $\mathrm{t}, \mathrm{c}_{\mathrm{M}, \mathrm{t}}$ is the return rate of the stock market in the time t. For the sake of simplicity, we will consider $\mathrm{N}=5$.

As in the traditional formula of the correlation, the time varying correlation lies in the $[1,-1]$ interval. In this study, we run the previous correlation estimator for the four investors' categories. So, we have estimated four correlation time series. To characterize the previous time series, we used Markov-switching model, which allows also to predict correlations states. So the following Markov-switching model will be used:

$$
c_{i, t}=\varphi_{S t}+\varepsilon_{t}, \quad N\left(0, \sigma_{S t}^{2}\right) \ldots
$$

Where terms $\varphi_{S t}, \sigma_{S t}^{2}$ are respectively the state-dependents correlation and variance of $c_{i, t} . S_{t}$ is an state variable, which equals 0 or 1 , according to correlation state, so $S_{t} \in\{0,1\}$. The logic of using this method is that, if the model gives us significant results for the two states, positive and negative correlations, this means that the correlations between the various investors' categories' trades and the stock market return are not constant and they are varying over the time. It means also that the signs of these correlations coefficients change over the time.

\subsection{Correlation Matrices' Analysis Results}

In the previous paragraph, we used Markov-switching model to test the stability of the correlation coefficients over the time. Table (4) shows the results of the Markov-switching model for this purpose. The results show that the correlations coefficients of foreign institutional investors' trading with Qatari stock market return have two significant states. These states are either positive or negative, so we could infer that these coefficients are varying over the time. The values of these correlations in the two states are 0.3830 , and -0.70313 respectively, with standard error $0.0658,0.0655$ respectively. With regards to foreign individual investors, table (5) displays its time varying correlations' coefficients with the Qatari stock market return. As it appears, the correlations coefficients of the positive and the negative states' values are respectively 0.5852 , and -0.3468 and the standard errors are respectively 0.0530 and 0.0610 . As Table (6), shows the Qatari institutional investors' time varying correlations' coefficients with the Qatari stock market return are respectively0.0934 and -0.7516 with respective standard error of 0.0724 and 0.1284 . Finally, Table (7) shows the Qatari individual investors' time varying correlations' coefficients with the Qatari stock market return whose values are respectively 0.6867 and -0.1998 with standard errors of 0.0463 and 0.1045 respectively. To explain better the idea of the correlations varying over the time, we drew the graphs of the coefficients. Figure (7) shows the time varying correlation coefficients between foreign institutional investors and Qatari stock market return from January 2008 to October 2012. It is obvious from the chart that there is volatility in the relation between foreign institutional investors and the whole market trend. On the other hand, figures (8), (9), (10) reflect the correlations of the foreign individual investors, Qatari institutional investors, and individual investors with the Qatari stock market return from January 2008 to October 2012. The charts also show that the varying the relations between the various investors' categories and the Qatari stock market index.

\subsection{Does the Investor's Correlation Matrixes Performance Violate Market Leaders Herding Assumptions?}

The previous results show that the relations between the trading behavior of the Qatari stock markets' leaders and the Qatari stock markets are varying over time, which sets us in confusion of our results about foreign investor's behaviors in the Qatari stock market. The results report that foreign institutional investors lead the market during the bull and the bear states, while the foreign individual investors and the Qatari institutions only lead the market in the bear states. The question here is: does the variation in the correlations' coefficients of the various investors' categories affect the results about the leadership of the foreign investors for the market? To answer this question, we will calculate the Markov transition probabilities matrix for the time varying correlations coefficients of the various investors' categories. The transition probabilities matrix calculates the probabilities of transformation of the time varying correlations' coefficients from one state, positive (negative) to the other or the probabilities of remaining in the same sate. For this purpose we will use the following equation:

$$
P_{(t)}=\left[\begin{array}{cc}
p_{c i}^{00} & 1-p_{c i}^{11} \\
1-p_{c i}^{00} & p_{c i}^{11}
\end{array}\right] \ldots
$$


$\mathrm{p}_{\mathrm{ci}}^{00}$ is the probability of continuation of the time varying correlations' coefficients of the investor $i$ with the stock market return in the positive state. $p_{\mathrm{ci}}^{11}$ reflects the probability of persistence of the time varying correlations' coefficients of the investor $i$ with the stock market return in the negative state. Since the values of the correlations' coefficients are between two limits, 1 and -1, the logistic functions, similarly, as in equations (3) and (4).

The base of our test is that if the probability of persistence in the positive correlation states is more than the probability of persistence in the negative correlations, so we expect that this category of investors could lead the market, provided that there are significant regressing coefficients between this investor's category, as a independent factor, and the stock market index, as an dependent factor. In other words, if the regression model reported that the foreign institutional investors, for example, lead the market and, in the same time, the probability of the positive correlation between foreign institutional traders and the stock market trends are more than the negative correlation between the foreign institutional trades and the stock market trends, we could conclude the stability of the leadership position of the foreign institutional investors for the whole market. The second parts in tables (4), (5), (6), (7) display the values of $p_{\mathrm{ci}}^{00}$ and $\mathrm{p}_{\mathrm{ci}}^{11}$ for every investor's category. It is considerable from table (4) that the values of $\mathrm{p}_{\mathrm{ci}}^{00}$ and $\mathrm{p}_{\mathrm{ci}}^{11}$ are respectively 0.9815 and 0.9632 . Furthermore, $\mathrm{p}_{\mathrm{ci}}^{00}>\mathrm{p}_{\mathrm{ci}}^{11}$, which means that the probability of being in positive correlation, between the foreign institutional investors and the whole market return, is larger than the probability of being in the negative state. On the other hand, table (5) illustrates the transition probability of the correlations coefficients of the foreign individual trading with the Qatari market. It is considerable that $\mathrm{p}_{\mathrm{ci}}^{00}$ value in this case is more than $\mathrm{p}_{\mathrm{ci}}^{11}$ value. Since the Markov-switching model supports foreign individual investors to lead the market only in the bear market state, so it is not necessary for the correlation coefficient to be positive all the time. Consequently, the transition probability is consistent with the results of the Markov-switching model in equation (5). The values of $\mathrm{p}_{\mathrm{ci}}^{00}$ and $\mathrm{p}_{\mathrm{ci}}^{11}$, as it is appeared in tables (6), (7) are varying also; while, $\mathrm{p}_{\mathrm{ci}}^{00}>\mathrm{p}_{\mathrm{ci}}^{11}$ in table (6) with the values 0.9632 and 0.9521 respectively. The opposite are in table (7) where $p_{c i}^{00}<p_{c i}^{11}$ with the values 0.7994 and 0.8783 respectively; whoever, the previous results is also consistent with the results in the table (2) about the assumption of stock market leadership via some investors categories. We could conclude from the previous analysis that, although the correlation coefficients of the various investors' categorize vary over time, foreign institutional investors still lead the Qatari stock market trends during the market states, positive and negative states.

\begin{tabular}{|c|c|c|}
\hline \multicolumn{3}{|l|}{ Table (4) } \\
\hline \multicolumn{3}{|c|}{$\begin{array}{l}\text { The table shows the results of running the Markov-switching model for the } \\
\text { foreign institutional investors' time varying correlations' coefficients with } \\
\text { the Qatari stock market return. }\end{array}$} \\
\hline \multicolumn{3}{|c|}{ the foreign institutional investors } \\
\hline & (1) & (2) \\
\hline Parameter & & p-value \\
\hline \multirow[b]{2}{*}{$\varphi_{0}$} & 0.3830 & \multirow{2}{*}{0.0000} \\
\hline & $(0.0658)$ & \\
\hline \multirow[b]{2}{*}{$\varphi_{1}$} & -0.70313 & \multirow{2}{*}{0.0000} \\
\hline & $(0.0655)$ & \\
\hline $\mathrm{p}_{\mathrm{t}}^{00}$ & 0.9815 & \\
\hline $\mathrm{p}_{\mathrm{t}}^{11}$ & 0.9632 & \\
\hline LogLik & -21.457 & \\
\hline$\overline{D W}$ & 0.8873 & \\
\hline$A I C$ & 1.0560 & \\
\hline$S C$ & 1.2812 & \\
\hline$H Q C$ & 1.1423 & \\
\hline
\end{tabular}

Note: The model is $c_{i, t}=\varphi_{S t}+\varepsilon_{t}$, where $N\left(0, \sigma_{S t}^{2}\right)$. The entries in brackets are the standard errors. Terms $\varphi_{S t}, \sigma_{S t}^{2}$ are respectively the state-dependents correlation and variance of $c_{i, t} . S_{t}$ is an state variable which equal 0 or 1 according to correlation state, so $S_{t} \in\{0,1\}$. 
Table (5)

The table shows the results of running the Markov-switching model for the foreign individual investors' time varying correlations' coefficients with the Qatari stock market return.

\begin{tabular}{ccc}
\hline & \multicolumn{2}{c}{ the foreign institutional investors } \\
\hline & $(1)$ & $(2)$ \\
\hline Parameter & & p-value \\
\hline$\varphi_{0}$ & 0.5852 & 0.0000 \\
& $(0.0530)$ & 0.0000 \\
\hline$\varphi_{1}$ & -0.3468 & \\
& $(0.0610)$ & \\
\hline $\mathrm{p}_{\mathrm{t}}^{00}$ & 0.8385 & \\
\hline $\mathrm{p}_{\mathrm{t}}^{11}$ & 0.9025 & \\
\hline LogLik & -20.632 & \\
\hline$D W$ & 1.2600 & \\
\hline$A I C$ & 1.0243 & \\
\hline$S C$ & 1.2494 & \\
\hline$H Q C$ & 1.1106 & \\
\hline
\end{tabular}

Note: The model is $c_{i, t}=\varphi_{S t}+\varepsilon_{t}$, where $N\left(0, \sigma_{S t}^{2}\right)$. The entries in brackets are the standard errors. Terms $\varphi_{S t}, \sigma_{S t}^{2}$ are respectively the state-dependents correlation and variance of $c_{i, t} . S_{t}$ is an state variable which equal 0 or 1 according to correlation state, so $S_{t} \in\{0,1\}$.

\section{Table (6)}

The table shows the results of running the Markov-switching model for the Qatari institutional investors' time varying correlations' coefficients with the Qatari stock market return.

\begin{tabular}{ccc}
\hline \multicolumn{3}{c}{ the foreign institutional investors } \\
\hline & $(1)$ & p-value \\
\hline$\varphi_{0}$ & 0.0934 & 0.1971 \\
& $(0.0724)$ & \\
\hline$\varphi_{1}$ & -0.7516 & 0.0000 \\
\hline $\mathrm{p}_{\mathrm{t}}^{00}$ & $(0.1284)$ & \\
\hline $\mathrm{p}_{\mathrm{t}}^{11}$ & 0.9632 & \\
\hline$L o g L i k$ & 0.9521 & \\
\hline$D W$ & -32.174 & \\
\hline$A I C$ & 0.8482 & \\
\hline$S C$ & 1.4297 & \\
\hline$H Q C$ & 1.6174 & \\
\hline
\end{tabular}

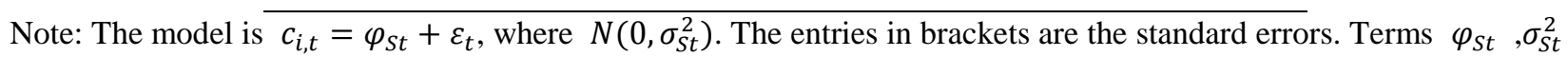
are respectively the state-dependents correlation and variance of $c_{i, t} . S_{t}$ is an state variable which equal 0 or 1 according to correlation state, so $S_{t} \in\{0,1\}$. 


\begin{tabular}{|c|c|c|}
\hline \multicolumn{3}{|l|}{ Table (7) } \\
\hline \multicolumn{3}{|c|}{$\begin{array}{l}\text { The table shows the results of running the } \\
\text { Markov-switching model for the Qatari individua } \\
\text { investors' time varying correlations' coefficients with the } \\
\text { Qatari stock market return. }\end{array}$} \\
\hline \multicolumn{3}{|c|}{ the foreign institutional investors } \\
\hline & $(1)$ & (2) \\
\hline Parameter & & p-value \\
\hline$\varphi_{0}$ & $\begin{array}{c}0.6867 \\
(0.0463)\end{array}$ & 0.0000 \\
\hline$\varphi_{1}$ & $\begin{array}{l}-0.1998 \\
(0.1045)\end{array}$ & 0.0000 \\
\hline$p_{t}^{00}$ & 0.7994 & \\
\hline $\mathrm{p}_{\mathrm{t}}^{11}$ & 0.8783 & \\
\hline LogLik & -26.172 & \\
\hline$D W$ & 1.2651 & \\
\hline$A I C$ & 1.2374 & \\
\hline$S C$ & 1.4625 & \\
\hline$H Q C$ & 1.3237 & \\
\hline
\end{tabular}

Note: The model is $c_{i, t}=\varphi_{S t}+\varepsilon_{t}$, where $N\left(0, \sigma_{S t}^{2}\right)$. The entries in brackets are the standard errors. Terms $\varphi_{S t}, \sigma_{S t}^{2}$ are respectively the state-dependents correlation and variance of $c_{i, t} . S_{t}$ is an state variable which equal 0 or 1 according to correlation state, so $S_{t} \in\{0,1\}$.

\section{The Importance of Study and Recommendations}

This study presents two measures for evaluating the role of the foreign investor in the local stock market. These measures enabled us to determine whether the foreign investor only leads the market during the bull (bear) state or he can also change the market states, bear or bull, by affecting the probability of the transition from one market state to another?

On the practical, the study enables the policy maker to evaluating the role of the foreign investors in the stock market. For example, if there is a significant relationship between the investor category and the stock market return in equation (5), but, there is no significant relation between the same investor category and the probability of the transition from one market state to another, this means that this investor only can lead the market during the business cycle. But he has not the ability to change the market state. In other words, this investor cannot make a crisis in the market.

On the other hand, if the investor, according to equation (6), (7) has the ability to change the market state from bear to bull or from bull to bear, so, this investor can lead the stock market to a crisis if he planned for that. In this case the policy maker should restrict the movement of this investor to avoid this risk.

\subsection{The Qatari Case}

As we displayed above, the foreign investors can't switch the Qatari stock market from one state to another. They only herd with the market trends causing prices bubbles without any benefit for the domestic market. In this section we present some proposed steps to minimize the harmful manners of the foreign investors; these steps are:

1) The government should encourage the role of market maker by increasing the incentives for the institutions to play this role. We see that the role of the market maker can control the leadership of any investor during the business cycle which may be harmful for the market and the small investor specially.

2) The foreign institutional investors should pay taxes for capital gains and dividends. It is thought that this procedure can determine the speculation by the foreign investors because it reduces the profit margin of the trading process. 
9.2 What if there are a Significant Relationship between the Foreign Investors' Categories and the Dynamics of Switching in Regime?

In this case the policy maker should restrict the foreign funds movements in the stock market to reduce the risk of a planned crisis may be started by the foreign investor. The proposed steps in this situation may include:

1) The foreign institutional investors shouldn't be allowed to buy more than a specific percentage of the issued stocks of any company. This percentage is predetermined by the capital authority.

2) When the foreign institutional investors need to exit from the market, foreign institutional investors shouldn't be allowed to sell more than a specific percentage from their portfolios on one day. This percentage is also previously determined by the capital authority.

3) We support the recommends of Elsiefy et al. (2015) which argue that there should be Capital Gains Tax paid when investor make profits from his shares. The Tax rate should be divided into two types, as in the US taxation rules, : long-term capital gains rate and short-term capital gains rate. The long-term rate should be less than the short-term rate to encourage investors to hold their assets and don't sell it.

4) The government should use subsidization and give cash subsidies to the investors how hold the stocks for long-run period to compensate them for the capital gains from selling their stocks.

\section{The Future Research}

In this paper we advise the government of the country which finds a significant relationship between the foreign investors' trades and the probability of switching of the market from one regime to other to restrict the movements of the funds of these investors. We concluded that by determining the allowed ownership percentage for the foreign investors. We intend in our future research to construct a model for determining the optimal allowed percentage for holding shares in the local firms by the foreign investors. It is planned also to create a model for choice the optimal percentage for buying and selling which the government should permit for to the foreign investors.

\section{Summary}

In this article, we investigated the foreign fund's movement in the stock market and its effect on the stock market return and the change in regime switching. First, we characterized the bull and bear market states in the Qatari Market to compare it with the other stock markets which have been previously studied. The empirical results show that the bull state in the Qatari Market has long run positive mean and low variance, while the bear state have a short run negative mean with high variance. So our results support the previous literature review. In the second part of the study, we tried to investigate if the foreign investor inters the market in order to only herding with the market trends while he has not the ability to switch the regime of the market or he has the full ability to push the market up and down, and change the trend of the market. We proposed a new adaptation of Hamilton (1989) to measure herding in the market and the ability to switch the market state (bull or bear). The model was divided into two parts. In the first part, we included the investor types' variable in the Hamilton (1989) model as an independent factor which measures the herding behavior of each investor type. The second part has considered TVTP in Markov-Switching model to measure the ability of the trader to shift the market form one state to another. We have found that, of the four investor categories, no one has full control of the market state switching. The unexpected surprise was that we found a significant negative relationship between the Qatari individual flows and the probability of persistence in the bull regime which means that Qatari individuals cannot predict the market trends; in other words they cannot time the market trends. We extended our analysis to examine the stability of the stability of the leadership position of the foreign institutional investor via investigating the time-varying correlations' coefficients of the four investors' categories with the Qatari stock market. The result concluded that, although the correlation matrixes of the various investors' types are time-varying, the foreign institutional investors still have the leadership position over the period of the study. Finally, we presented some recommendations which we think that it is important for the policy maker to prevent manipulating by foreign institutional investors and by all manipulators at all. For the stock market to have more stability, we highly recommend for the Qatari Stock Authority to add some regulations regarding foreign institutional investors.

\section{References}

Ang, A. \& J. Chen. (2002). Asymmetric correlations of equity portfolios. Journal of Financial Economics, 63(3), 443-494. https://doi.org/10.1016/S0304-405X(02)00068-5

Brennan, M., Cao, H. (1997). International portfolio investment flows. Journal of Finance, 52, 1851- 1880. https://doi.org/10.1111/j.1540-6261.1997.tb02744.x 
Chang, C. (2010). Herding and the role of foreign institutions in emerging equity markets. Pacific-Basin Finance Journal, 18, 175-185. https://doi.org/10.1016/j.pacfin.2009.11.001

Chauvet, M., \& Potter, S. (2000). Coincident and leading indicators of the stock market. Journal of Empirical Finance, 7, 87-111. https://doi.org/10.1016/S0927-5398(99)00015-8

Chen ,Shiu-Sheng. (2007). Does Monetary Policy Have Asymmetric Effects on Stock Returns? Journal of Money, Credit and Banking, 39(2-3), 667-688, March-April. https://doi.org/10.1111/j.0022-2879.2007.00040.x

Choe, H., Kho, B., Stulz, R. (1999). Do foreign investors destabilize stock markets? The Korean experience in1997. Journal of Financial Economics, 40, 31-62.

Choi, N. Skiba, H. (2014). Institutional Herding in International Markets. University of Wyoming, College of Business, Department of Economics and Finance. Working Paper.

Durland J.M, Mc Curdy T. (1994). Duration-Dependent Transitions in a Markov Model of U.S. GNP Growth. Journal of Business \& Economic Statistics, 12(3).

Engle, R. (2002). Dynamic conditional correlation: A simple class of multivariate generalized autoregressive conditional heteroskedasticity models. Journal of Business and Economic Statistics, 20(3), 339-350. https://doi.org/10.1198/073500102288618487

Engle, R.F. \& K. Sheppard. (2001). Theoretical and empirical properties of dynamic conditional correlation multivariate GARCH, Working Paper no. 2001-15, UCSD.

Engle, R.F., C.H. Hong, \& A. Kane. (1990). Valuation of variance forecasts with simulated option markets, Working Paper no. 90-16, UCSD.

Engle, R.F., T. Ito, \& W.L. Lin. (1990). Meteor showers or heat waves? Heteroscedastic intra daily volatility in the foreign exchange market. Econometrica, 58(3), 525-545. https://doi.org/10.2307/2938189

Elsiefy, Elsayed. Abozaid, Abdulazeem. (2015). The negative effects of stocks and the way to avoid it; Legitimate economic approach. Qatar Foundation.

Filardo, Andrew J. (1994). Business-Cycle Phases and Their Transitional Dynamics. Journal of Business \& Economic Statistics, 12, 299-308.

Froot, K., Scharfstein, D., Stein, J. (1992). Herd on the street: Informational inefficiencies in a market with short term speculation. Journal of Finance, 47, 1461- 1484. https://doi.org/10.1111/j.1540-6261.1992.tb04665.x

Froot, K., O'Connell, P., Seasholes, M. (2001). The portfolio flows of international investors. Journal of Financial Economics, 59, 151- 193. https://doi.org/10.1016/S0304-405X(00)00084-2

Hamilton, J.D. (1989). A New Approach to the Economic Analysis of Non stationary Time Series andthe Business Cycle. Econometrica, 57(2), 357-384. https://doi.org/10.2307/1912559

Jirasakuldech, B. Emekter, R. (2015). Foreign Investors' Trading Behavior in Response to Crises: Evidence from Thailand. International Research Journal of Applied Finance, 4(1), 1-36.

Kamesaka, A. Nofsinger, J. Kawakita, H. (2003). Investment patterns and performance of investor groups in Japan. Pacific Basin Finance Journal, 11, 1 -22. https://doi.org/10.1016/S0927-538X(02)00095-1

Karolyi, A. (2002). Did the Asian financial crisis scare foreign investors out of Japan? Pacific Basin Finance Journal, 10(4), 411 -442. https://doi.org/10.1016/S0927-538X(02)00067-7

Kyle, Albert S. (1985). Continuous auctions and insider trading. Econometrica, 53, 1315-1336. https://doi.org/10.2307/1913210

Longin, F. \& B. Solnik. (1995). Is the correlation in international equity returns constant: 1960-1990? Journal of International Money and Finance, 14(1), 3-26. https://doi.org/10.1016/0261-5606(94)00001-H

Longin, F. \& B. Solnik. (2001). Extreme correlation of international equity markets. Journal of Finance, 56(2), 649-676. https://doi.org/10.1111/0022-1082.00340

Maheu, John M. \& McCurdy, Thomas H. (2000). Identifying bull and bear markets in stock returns. Journal of Business and Economic Statistics, 18(1), 100-112.

Maheu, John M. \& McCurdy, Thomas H. (2009). Extracting bull and bear markets from stock returns. University of Toronto, Working Paper. 
Patnaik, I. Shah, A. \& Singh, N. (2013). Foreign Investors Under Stress: Evidence from India. IMF Working Paper.

Shyu, J., \& Sun, H-M. (2010). Do Institutional Investors Herd in Emerging Markets? Evidence from the Taiwan Stock Market. Asian Journal of Finance \& Accounting, 2(2), 1-19. https://doi.org/10.5296/ajfa.v2i2.456

Tse, Y.K. (2000). A test for constant correlations in a multivariate GARCH model. Journal of Econometrics, 98(1), 107-127. https://doi.org/10.1016/S0304-4076(99)00080-9

Wu, W. Wan, D. \& Cai, D. (2011). Are qualified foreign institutional investors real investors or speculators? Evidence from China. SSRN Working Paper Series.

\section{Appendix}

Figure (1) the filtered Regime probability of being in the bull state when $\mathrm{P}(\mathrm{S}(\mathrm{t})=0)$

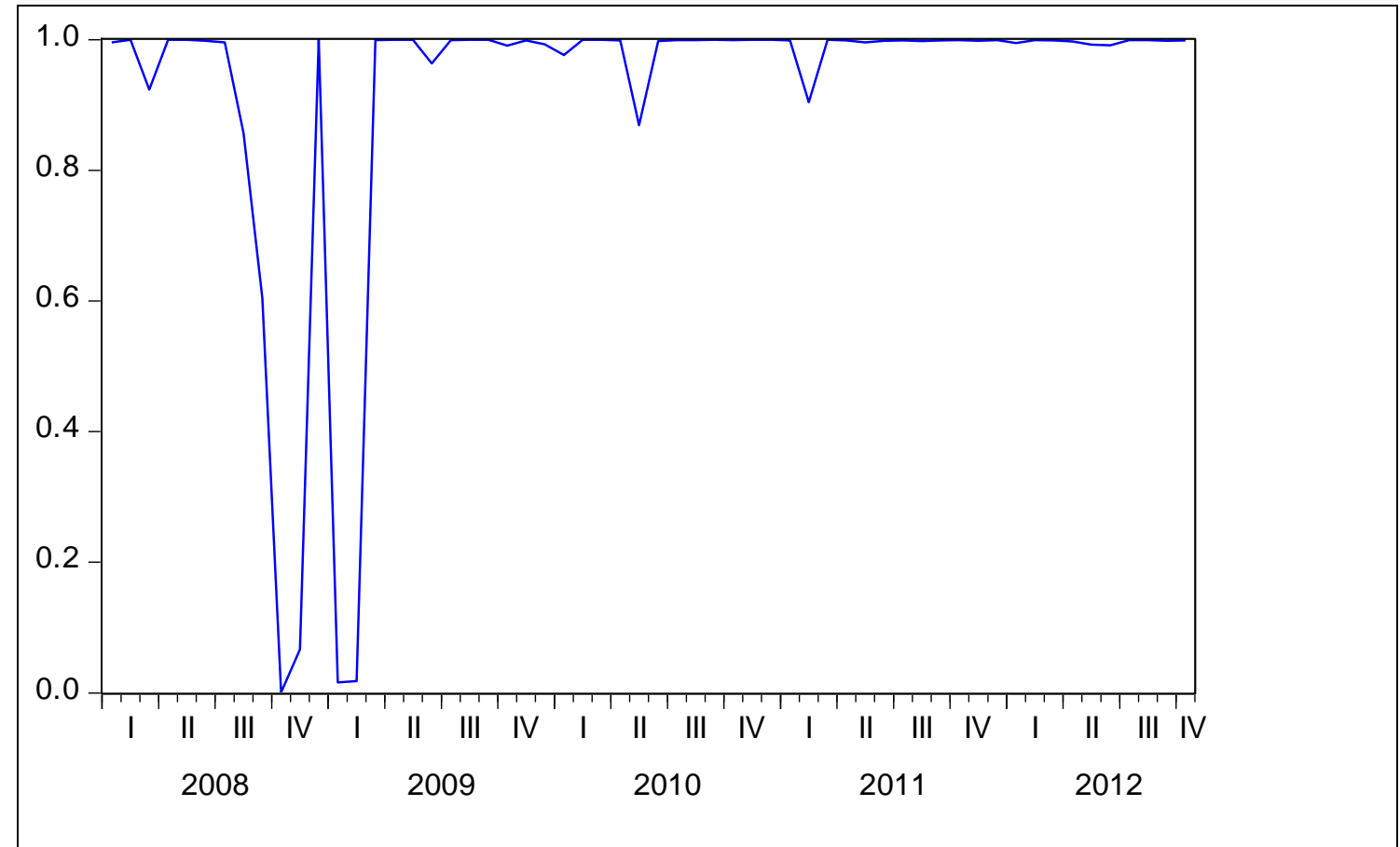


Figure (2) the filtered Regime probability of being in the bear state when $P(S(t)=1)$

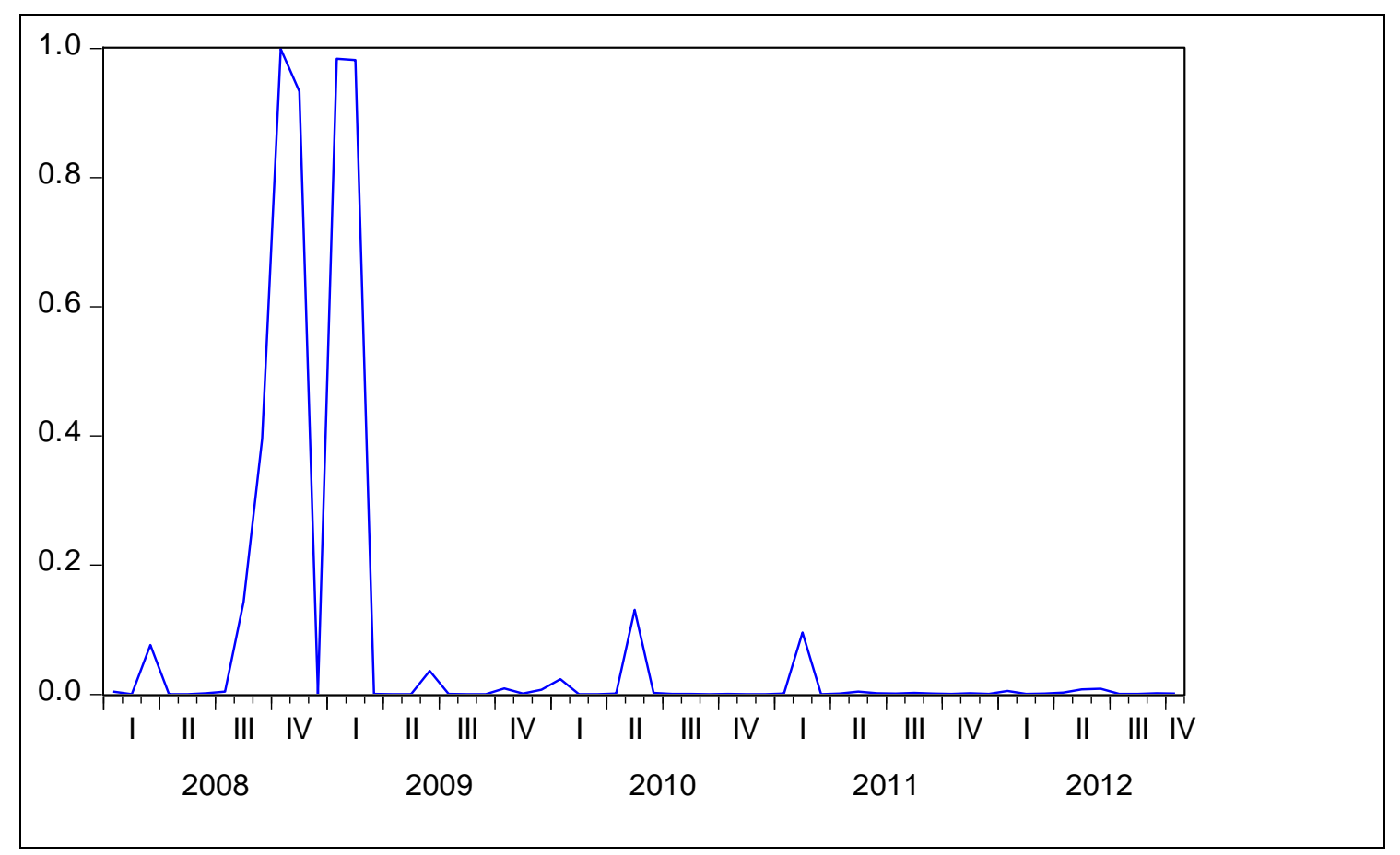

Figure (3): Time-Varying Transition Probabilities after including foreign individuals and foreign institutions factors in the TVTM. $\operatorname{Pr}(\mathrm{S}(\mathrm{t})=0 \mid \mathrm{S}(\mathrm{t}-1)=0)$

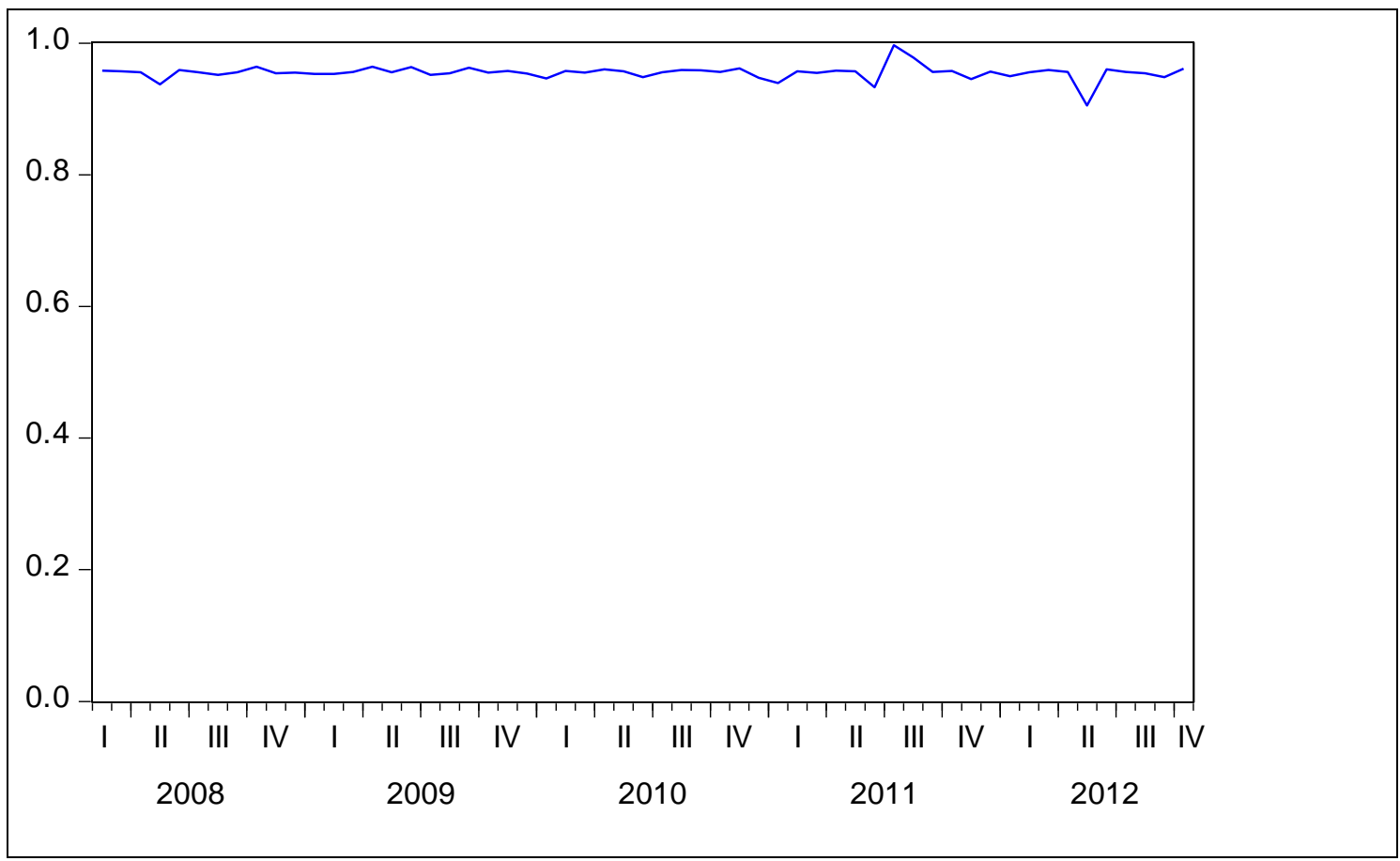


Figure (4): Time-Varying Transition Probabilities after including foreign individuals and foreign institutions factors in the TVTM. $\operatorname{Pr}(\mathrm{S}(\mathrm{t})=1 \mid \mathrm{S}(\mathrm{t}-1)=1)$.

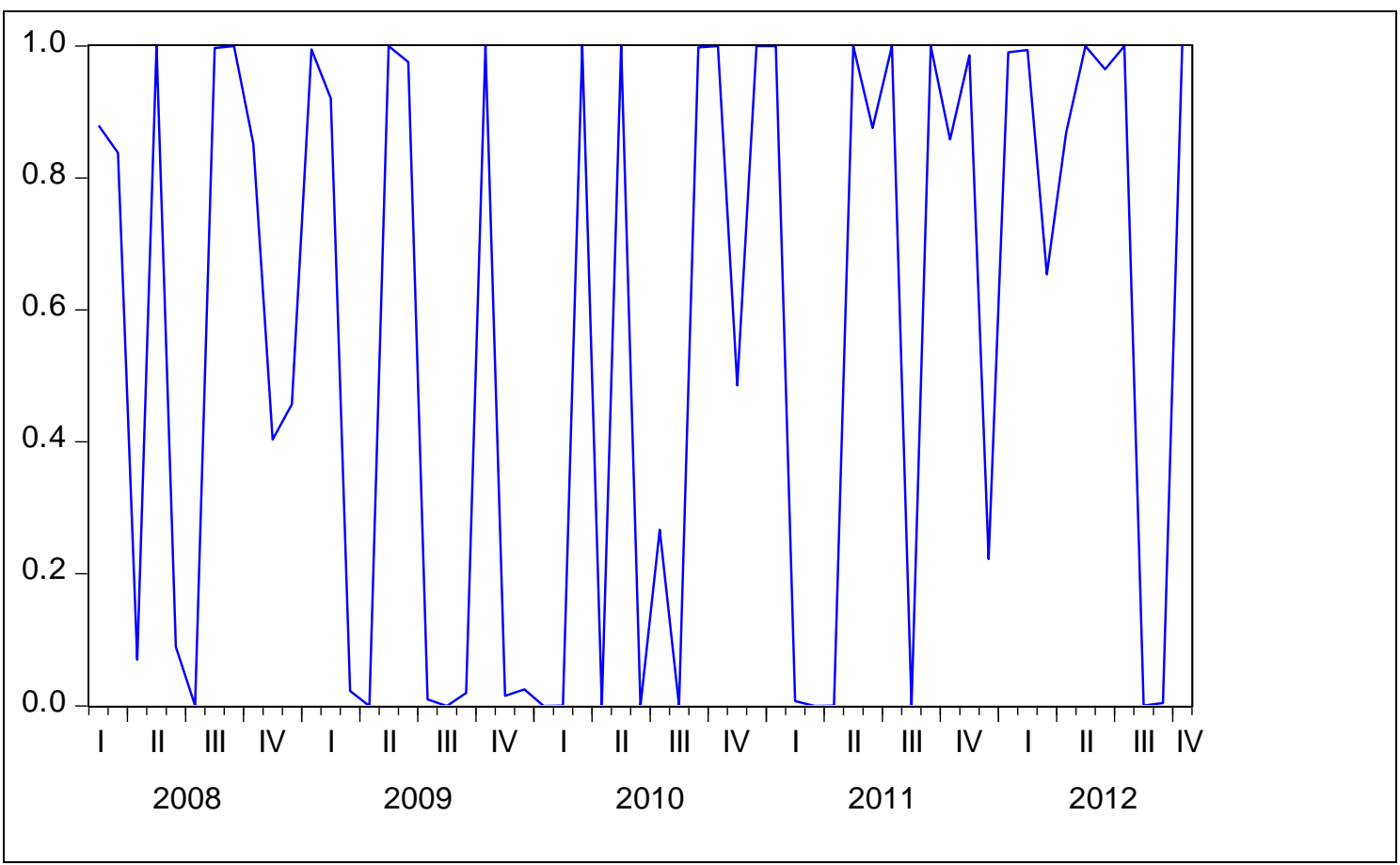

Figure (5): Time-Varying Transition Probabilities after including Qatari individuals and Qatari institutions factors in the TVTM. $\operatorname{Pr}(\mathrm{S}(\mathrm{t})=0 \mid \mathrm{S}(\mathrm{t}-1)=0)$.

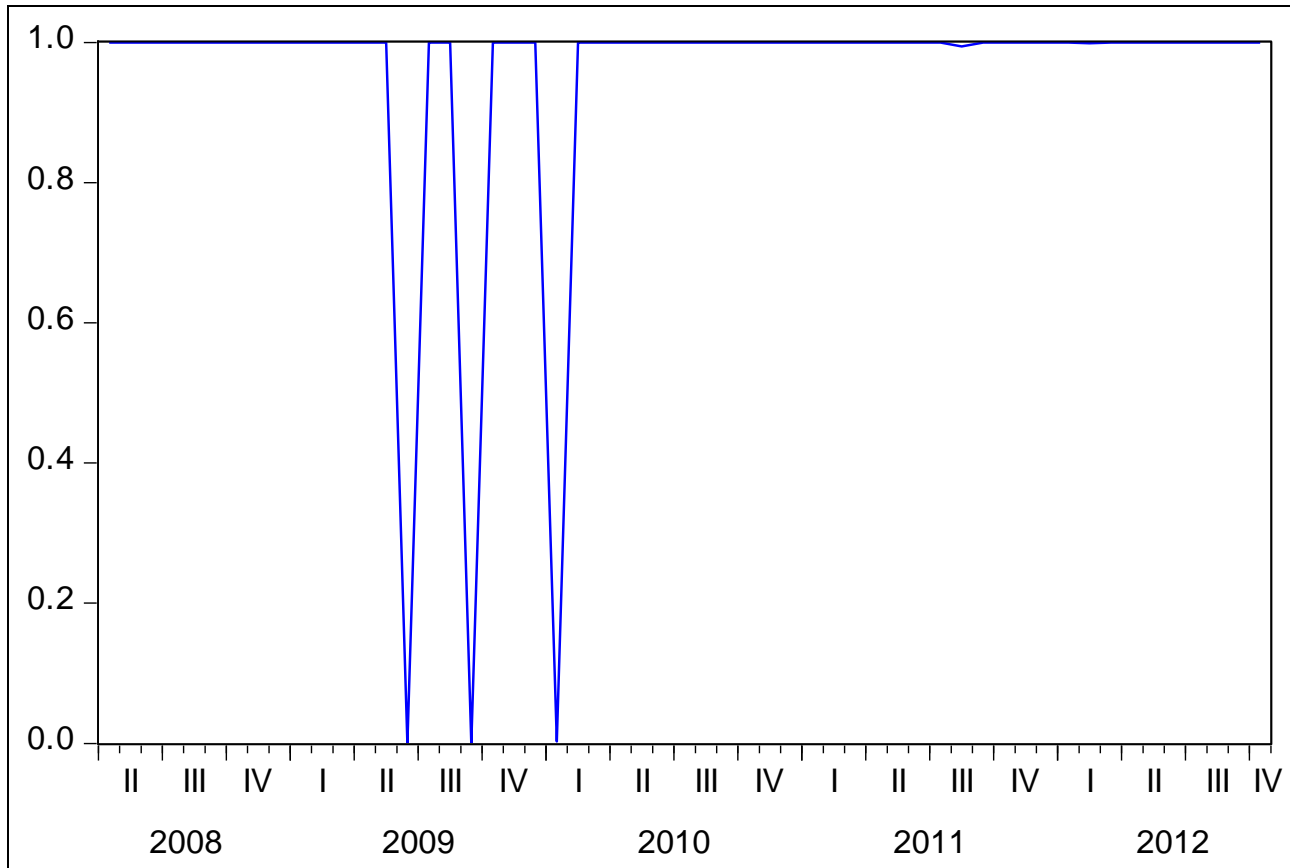


Figure (6): Time-Varying Transition Probabilities after including Qatari individuals and Qatari institutions factors in the TVTM. $\operatorname{Pr}(\mathrm{S}(\mathrm{t})=1 \mid \mathrm{S}(\mathrm{t}-1)=1)$.

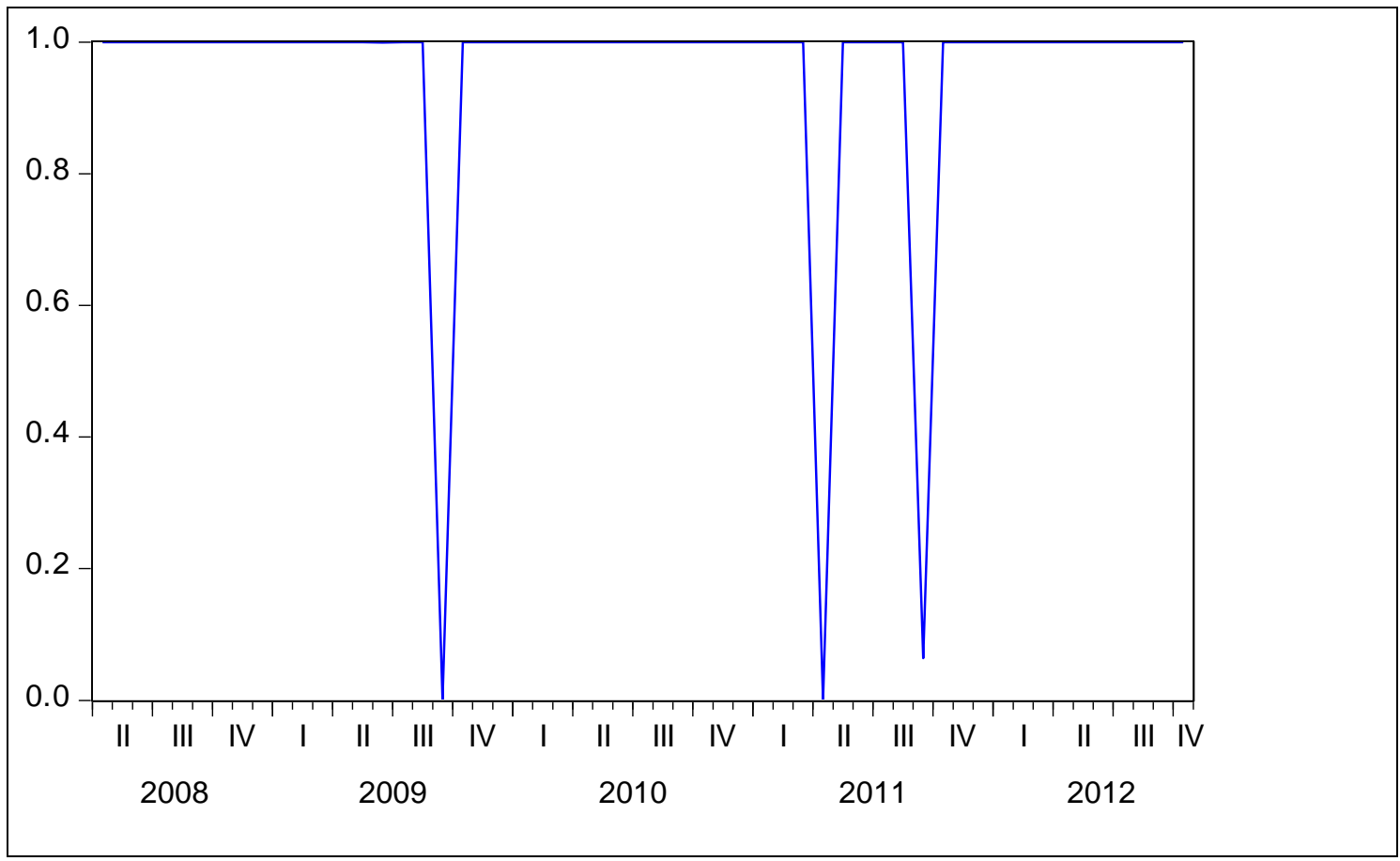

Figure (7) the time varying correlation coefficients between the foreign institutional investors and Qatari stock market return during from January 2008 to October 2012.

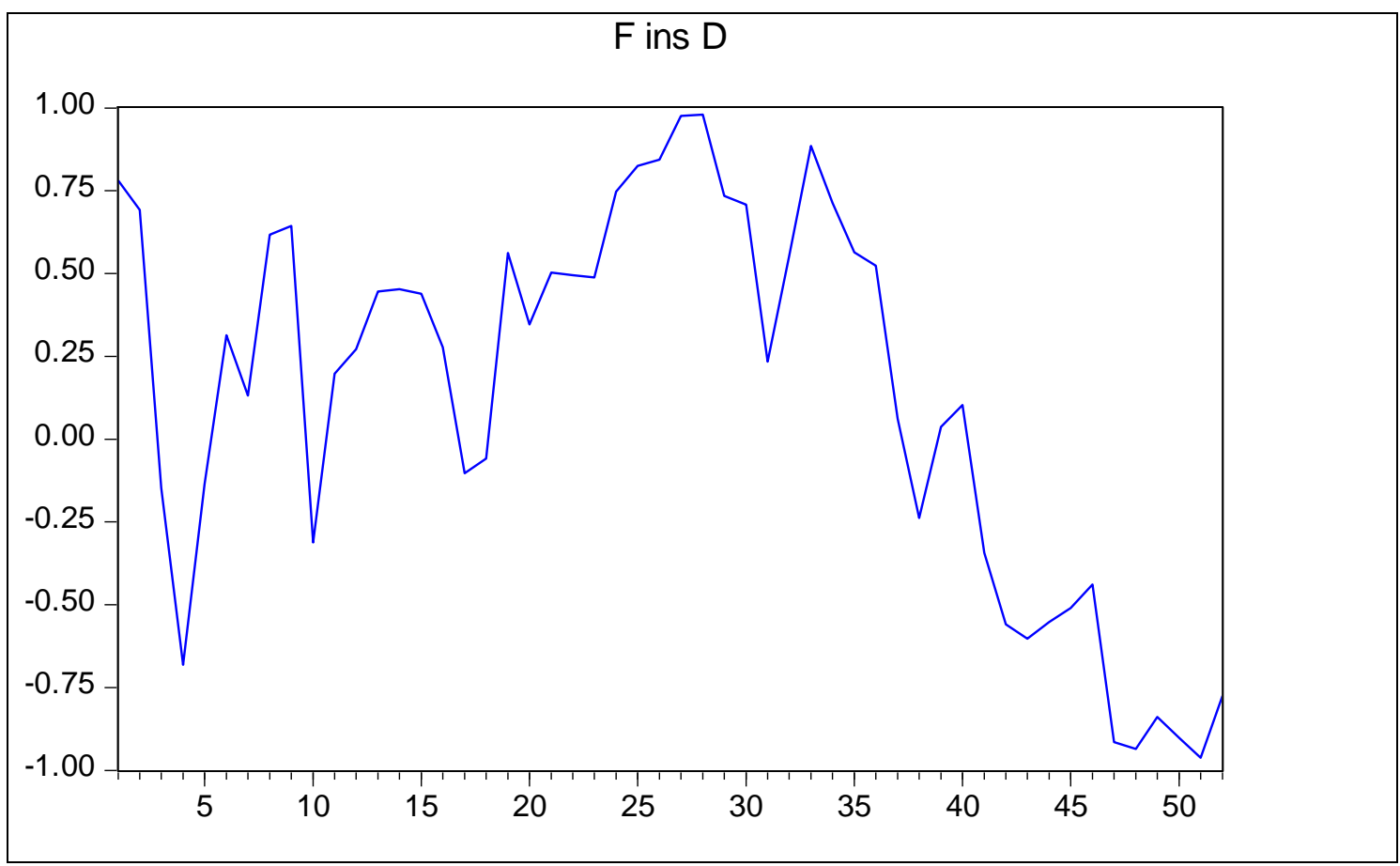


Figure (8) the time varying correlation coefficients between the foreign individual investors and Qatari stock market return during from January 2008 to October 2012.

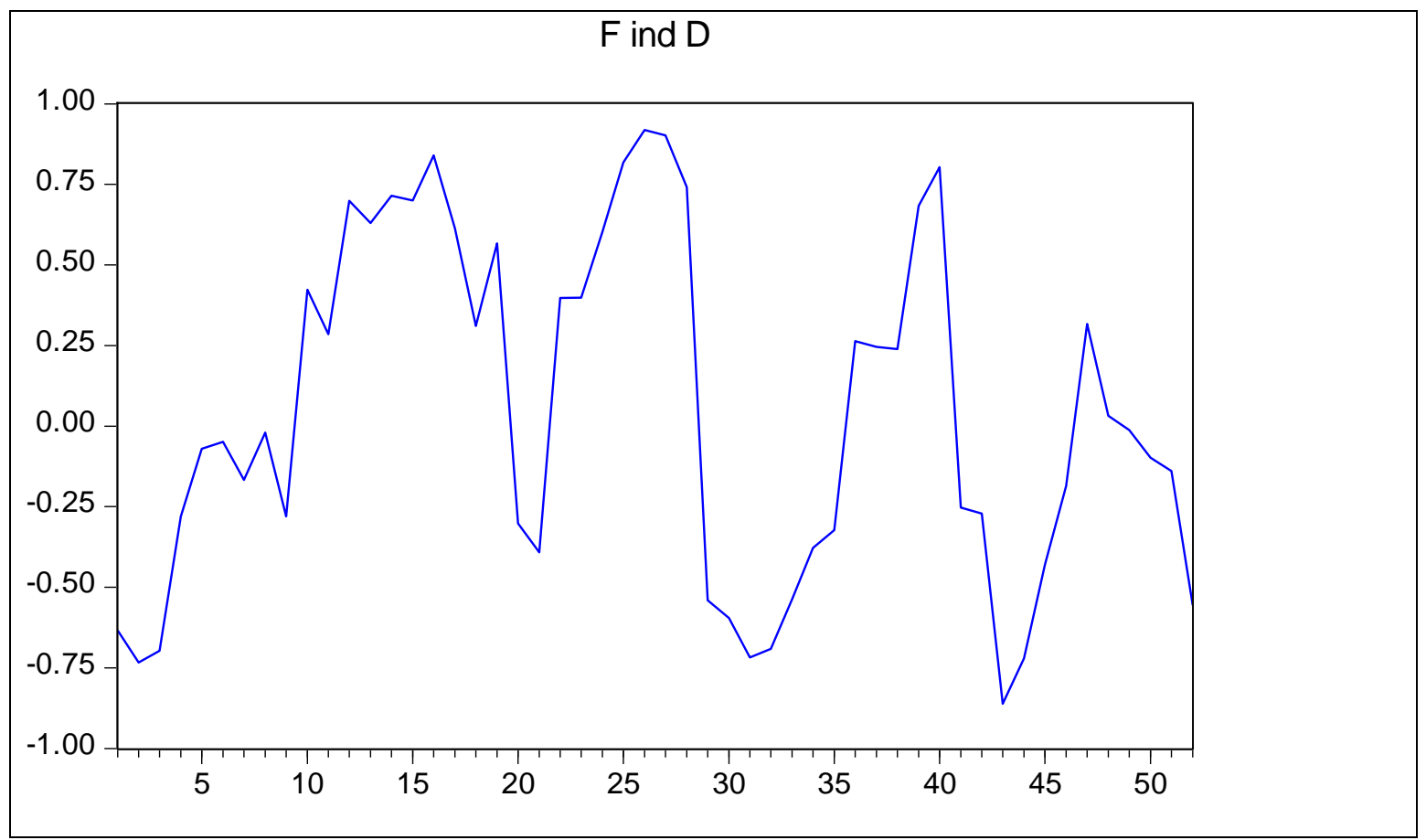

Figure (9) the time varying correlation coefficients between the Qatari institutional investors and Qatari stock market return during from January 2008 to October 2012.

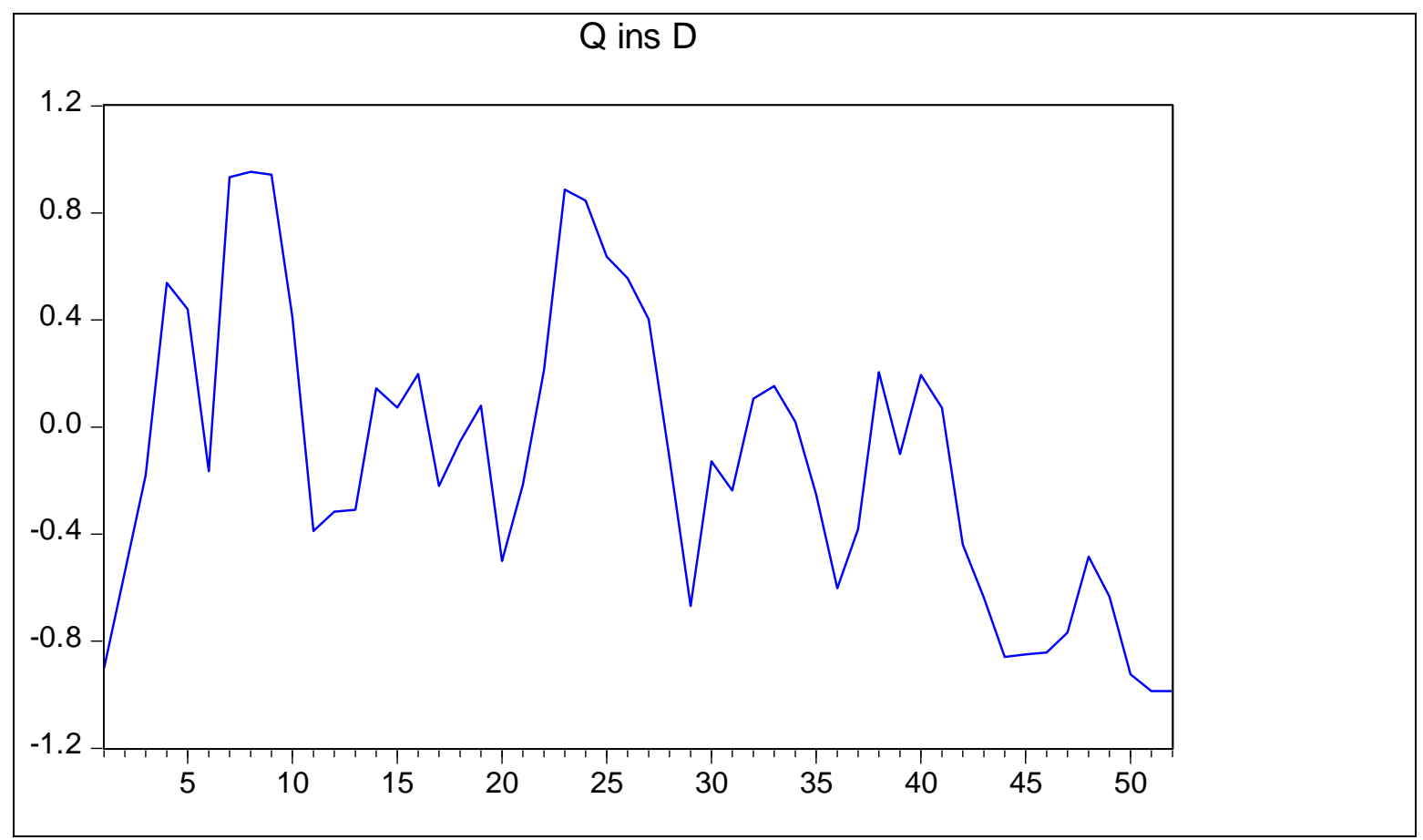


Figure (10) the time varying correlation coefficients between the Qatari individual investors and Qatari stock market return during from January 2008 to October 2012.

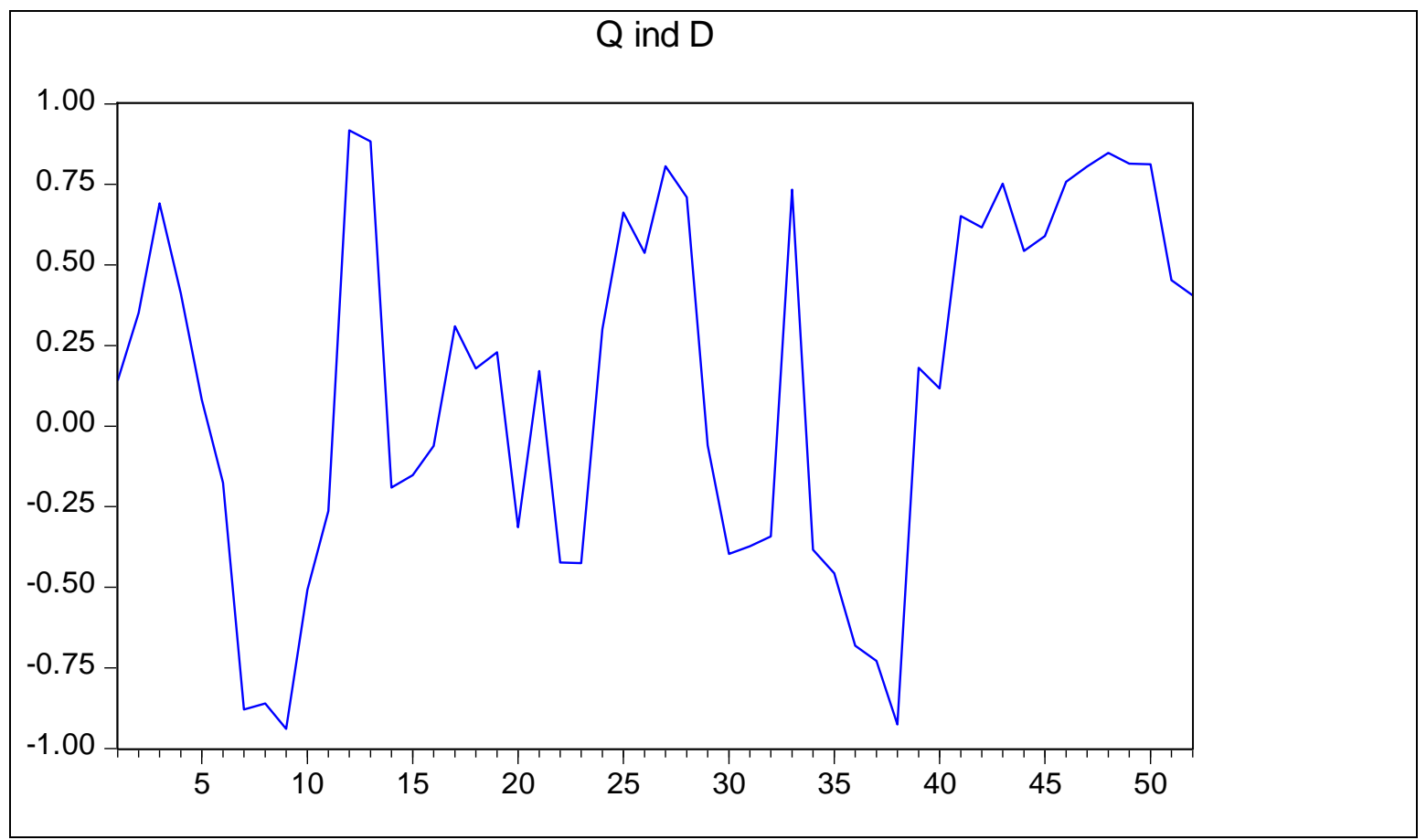

